\title{
Tatalaksana Trauma Wajah dengan Panfasial Fraktur
}

\author{
Lina Marlina,* Bambang S.R.Utomo, Fransiskus H. Poluan \\ Departemen Ilmu KesehatanTelinga Hidung Tenggorok-Bedah Kepala Leher \\ Fakultas Kedokteran Universitas Kristen Indonesia/Rumah Sakit Universitas Kristen Indonesia \\ Jakarta
}

\begin{abstract}
Abstrak
Fraktur pada wajah dapat menyebabkan defisit fungsional dan estetika jika tidak ditangani dengan baik. Tatalaksana akut yang tepat dari fraktur wajah harus didasarkan pada evaluasi cepat dan menyeluruh. Keberhasilan rekontruksi wajah merupakan keadaan darurat yang perlu dievaluasi dalam waktu 24 jam dari trauma. Berbagai jenis reduksi dan fiksasi tergantung pada fungsi, lokasi, jenis fraktur, dan usia pasien. Kasus ini diajukan untuk memperlihatkan keberhasilan tatalaksana trauma akut maksilofasial. Dilaporkan seorang laki-laki 37 tahun dengan panfasial fraktur yang dilakukan reduksi dan fiksasi 3 hari setelah trauma dengan pemasangan plat dan sekrup, serta fiksasi mukoginggival kombinasi antara arch bardan quickfix. Reduksi, reposisi dan fiksasi dilakukan setelah edema mukosa hebat disertai kombinasi antara arch bar dan quickfix pada mukoginggival merupakan salah satu alternatif untuk mengurangi risiko perdarahan dan memudahkan reposisi.
\end{abstract}

Kata kunci: fraktur wajah, panfasial fraktur,edema mukosa.

\section{Management of Maxillofacial Traumawith Panfacial Fracture}

\begin{abstract}
Facial fractures can cause functional and aesthetic deficits if not treated properly. Appropriate acute management of facial fractures should be based on a rapid and thorough evaluation. Successful facial reconstruction is an emergency that needs to be evaluated within 24 hours of trauma. Different types of reduction and fixation depend on the function, location, type of fracture, and the age of the patient. This case is presented to demonstrate the success of acute maxillofacial trauma management. Reported a 37-year-old man with a facial fracture who underwent reduction and fixation 3 days after trauma with plate and screw installation, and combination mucogingival fixation between arch bar and quickfix. Reduction, reposition and fixation performed after severe mucosal edema accompanied by a combination of arch bar and quickfix on the mucogingival is an alternative to reduce the risk of bleeding and facilitate repositioning.
\end{abstract}

Keywords: facial fracture, panfacial fracture, mucosal edema.

*LM: Penulis Koresponden; E-mail: hendrika.lina@gmail.com 


\section{Pendahuluan}

Fraktur wajah terjadi paling umum pada laki-laki, penyebab paling sering fraktur wajah adalah kecelakaan kendaraan bermotor, kekerasan interpersonal, jatuh, dan kecelakaan yang diakibatkan oleh olah raga. ${ }^{1}$ Di Amerika Utara dan Eropa, fraktur karena kekerasan jumlahnya meningkat. Fraktur hidung merupakan fraktur yang sering ditemui, diikuti oleh fraktur dentoalveolar dan mandibula, midface, patah tulang dasar orbita, dan sinus, kemudian fraktur frontal. ${ }^{2}$

Dalam trauma maxillofasial, penilaian saluran napas bagian penting dari pemeriksaan klinis. Obstruksi jalan napas atas dapat diakibatkan perdarahan, edema, fraktur komunitif atau displacement dan benda asing seperti gigi palsu sehinggajalan napas ditangani sebelum evaluasi lain. Pemeriksaan klinis dan pencitraan radiologi merupakan baku emas menegakan diagnosis, perencanaan, dan pengelolaan fraktur maksilofasial. $^{3}$

Tatalaksana akut dilakukan 72 jam setelah trauma, rekonstruksi segera dalam waktu dua minggu dan rekonstruksi tunda setelah dua minggu. ${ }^{4}$ Pada fraktur mandibular penatalaksanaan paling sering dilakukan adalah reduksi tertutup dengan fiksasi maksilomandibula, observasi melalui modifikasi diet/aktivitas dan reduksi terbuka dengan fiksasi internal. Menurut Ellis, ${ }^{5}$ reduksi tertutup diindikasikan pada fraktur kondilus untuk memperbaiki suplai darah ke fragmen, dan fraktur subkondilar. Fraktur zygomaticomaxillary complex (ZMC) dapat ditangani dengan reduksi terbuka atau tertutup tergantung pada tingkat displacement dan mobilitas pasca reduksi. Menurut Hermund et al., ${ }^{6}$ patah tulang zigomatikus, penundaan singkat (72 jam) dalam rekonstruksi lebih menguntungkan karena edema pada jaringan lunak mungkin dapat meminimalkan kecacatan.

Tujuan penulisan laporan kasus ini adalah untuk memperlihatkan keberhasilan rekonstruksi pada trauma akut Maksilofasial

\section{Laporan Kasus}

Seorang laki-laki berusia 37 tahun, datang ke Intalasi Gawat Darurat Rumah Sakit Umum Universitas Kristen Indonesia, pada tanggal 23 maret 2018 dengan keluhan utama, luka memar seluruh bagian wajah, hidung tersumbat dengan keluhan lain mimisan, kebas disekitar wajah kiri dan kanan, mulut tidak dapat ditutup. Pemeriksaan fisik, keadaan umum dalam batas normal, status lokalis wajah didapatkan edema, hematom, raccoon eyes, pergerakan bola mata dalam batas normal, visus normal, sensibilitas wajah kiri dan kanan menurun (parastesia). Pada pemeriksaan hidung didapatkankavum nasi sempit disertai edema mukosa, krusta dan bekuan darah. Mulut maloklusi, pergerakan rahang terbatas, sulit menutup mulut. Didapatkan terdapat vulnus laserasi multipel pada dentoalveolar (Gambar 1).
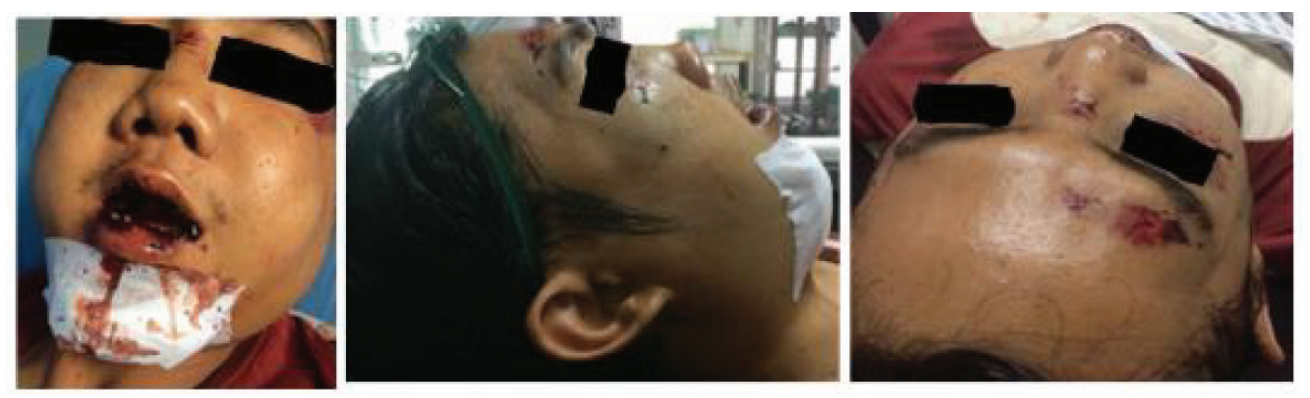

Gambar 1. Gambaran klinis penderita sebelum operasi. Edema maksilofasial, trismus positif, deformitas, krepitasi os nasal, os zigomaticus, dan struktur maksilofasial, epistaksis laten, penglihatan baik, gerakan bola mata terganggu, orofaring sulit dinilai, laserasi mukoginggival berat 
Pada pemeriksaan penunjang nasoendoskopi sulit dilakukan, laboratorium, dan rontgen toraks dalam batas normal. Pada gambaran radiologis menggunakan CT Scan 3D ditemukan fraktur os. Nasal, fraktur dinding anterior, inferior, superior maksilaris kiri dan kanan, fraktur simfisis mandibular, fraktur kompleks zigomatikus kiri dan kanan, fraktur dasar rima orbita kanan (Gambar 2). Pasien didiagnosis dengan panfasial fraktur.

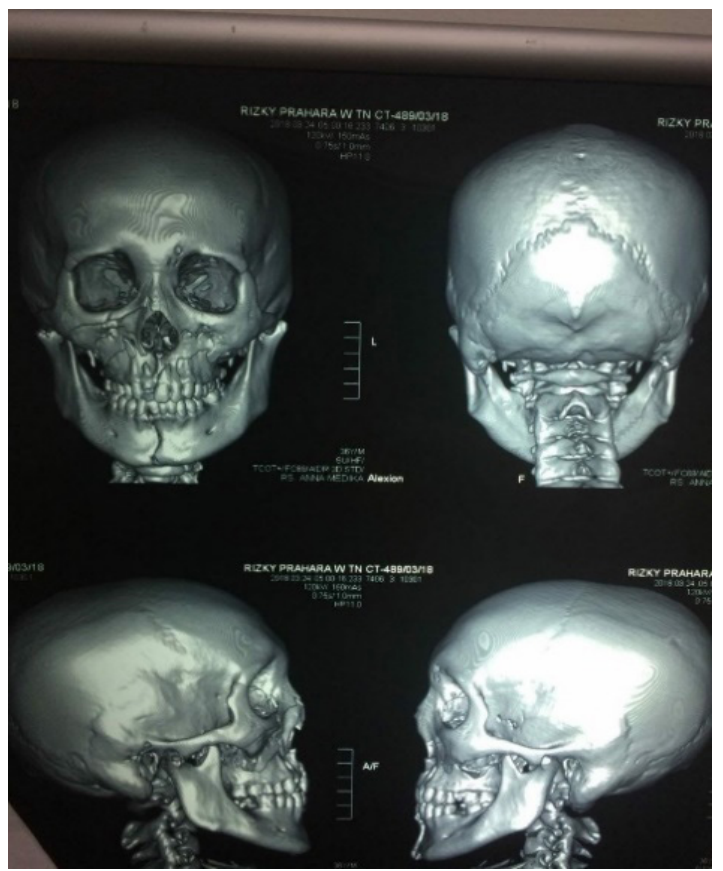

Gambar 2. CT Scan 3 dimensi pasien sebelum operasi. Tampak fraktur os. Nasal komplit, fraktur dinding anterior, inferior, superior maksilaris kiri dan kanan, fraktur simfisis mandibular, fraktur kompleks zigomatikus kiri dan kanan, fraktur dasar rima orbita kanan

Pasien direncanakan rekonstruksi dengan reduksi terbuka internal fiksasi, setelah edema mukosa berkurang (72 jam pasca trauma).

Pada tanggal 31 Maret 2018, dilakukan tindakan rekontruksi dengan reduksi terbuka dan internal fiksasi pada os maksilaris bilateral, reposisi os nasal, imobilisasi mandibula dengan pemasangan kombinasi antara arch bar pada ginggiva superior dan quick fix pada ginggiva inferior (Gambar 3). Pasien dirawat selama 10 hari di rumah sakit, hingga selang nasogastrik pasien dapat dilepas. Setelah satu minggu pasien kontrol untuk evaluasi, dan fiksasi mandibula dilonggarkan secara bertahap.

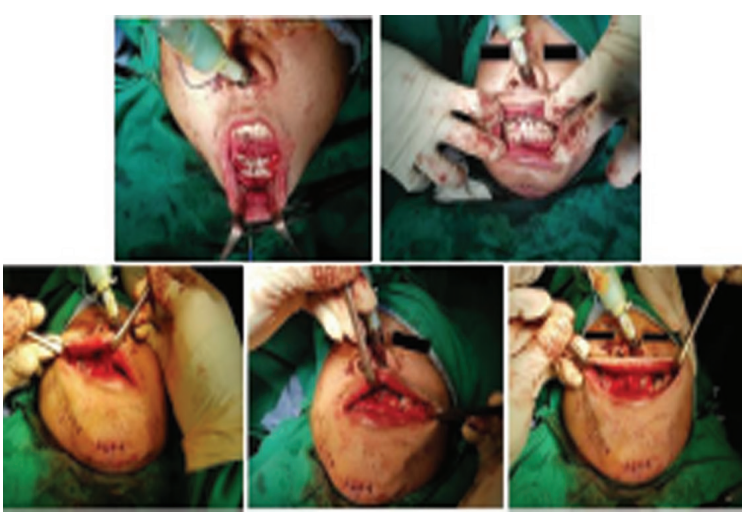

Gambar 3. Intra Operasi. Dilakukan tindakan rekonstruksi dengan reduksi terbuka dan internal fiksasi pada os maksilaris bilateral, reposisi os nasal, imobilisasi mandibula dengan pemasangan kombinasi antara arch bar pada ginggiva superior dan quick fix pada ginggiva inferior

Saat kontrol empat minggu kemudian, dilakukan pelepasan fiksasi mandibula (pelepasan arch bar dan quick fix). Pasien dapat buka tutup mulut dengan baik, dan parestesia wajah kiri dan kanan menghilang (Gambar 4).

Setelah satu tahun pasca operasi pergerakan rahang baik, gangguan sensibilitas wajah tidak ada, pasase udara kavum nasi tidak ada sumbatan dan simetris, penciuman baik. (Gambar 5)

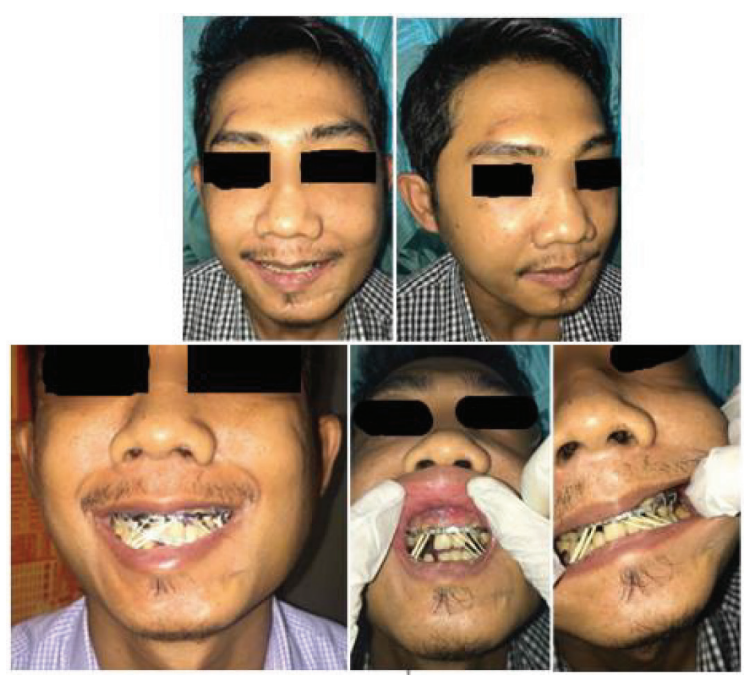


Gambar 4. Empat minggu post operasi. Quick fix (kawat dan plate eksternal mukoginggival) dibuka secara bertahap, pasien dapat buka tutup mulut dengan baik, parestesia wajah kiri dan kanan menghilang, dan pergerakan bola mata 9 arah baik.

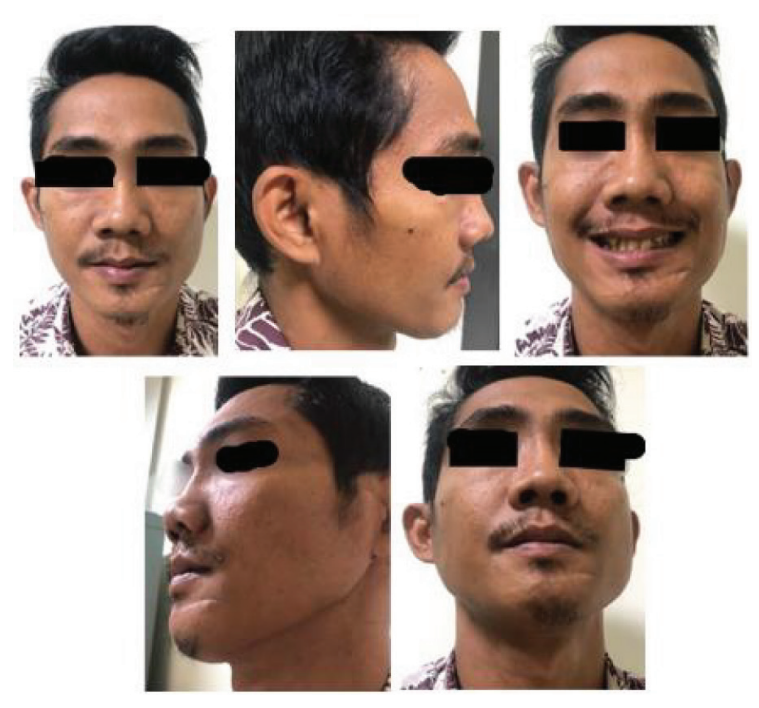

Gambar 5. Satu tahun post operasi, pergerakan rahang baik, gangguan sensibilitas wajah tidak ada, pasase udara cavum nasi tidak ada sumbatan dan simetris, penciuman baik.

\section{Diskusi}

Definisi fraktur panfasial mencakup komponen sepertiga bawah wajah, sepertiga tengah, dan sepertiga atas sering terjadi dalam fraktur kombinasi. Fraktur panfasial diakibatkan mekanisme energi tinggi seperti tabrakan kendaraan bermotor dan luka tembak. Cedera maksilofasial bilateral biasa terjadi akibat kecelakaan lalu lintas. Intervensi bedah dilakukan lebih dini untuk menghindari deformitas pasca operasi atau estetika buruk. $^{7}$

Tengkorak wajah terdiri dari empat daerah penopang vertikal dan empat bagian penompang horizontal. Daerah tulang ini lebih tebal dan dapat menentukan bentuk wajah seseorang. Proyeksi midface, dan lebar midface, di samping memulihkan hubungan oklusal. ${ }^{8}$ Penopang medial berada di sepanjang tulang depan hidung ke alveolus maksila anterior. Penopang maksilaris zigomatikus lateral meluas sepanjang zigoma dan tulang malar ke alveolus maksila lateral, Penopang pterigomaksila memiliki komponen medial yang memanjang dari posterior alveolus dan palatum ke dasar kranial, dan komponen lateral yang memanjang dari lempeng pterigoid lateral ke sayap yang lebih besar dan dinding lateral sfenoid. ${ }^{9}$

\section{Prinsip Rekonstruksi}

Secara anatomi tatalaksana fraktur panfasial dapat dilakukan dengan dua pendekatan klasik, yaitu dengan pendekatan Bottom up \& Inside out dengan melakukan rekonstruksi dari os mandibular ke os frontalis dan Top down \& outside in, yaitu rekonstruksi yang dilakukan dari os frontalis ke os mandibular. Fiksasi maksilomandibula dilakukan untuk memastikan oklusi maksila yang tepat. Pada bagian zigomatikus dilakukan reduksi di sisi dekstra dan sinistra untuk memperbaiki dimensi transversal dan antero-posterior wajah. Berbagai sayatan kulit dan metode osteosintesis telah dianjurkan, tetapi tidak ada konsensus di antara ahli bedah untuk perawatan fraktur wajah. Potensi komplikasi sayatan yaitu: alopesia pada bekas luka, komplikasi sensorik dan lain-lain. Sayatan lokal digunakan untuk menstabilkan dan memperbaiki fragmen yang patah dalam kasus ini. Yang et al., ${ }^{10}$ melaporkan efek memuaskan setelah mengikuti urutan Bottom up \& inside out yang membantu menstabilkan fraktur mandibula. Daerah zigomatik direduksi di sisi kanan dan kiri untuk memperbaiki dimensi transversal dan antero-posterior wajah.

\section{Kesimpulan}

Pada rekonstruksi wajah pasca trauma, keberhasilan rekonstruksi pada trauma akut Maksilofasial, untuk mengurangi perdarahan 
dan risiko komplikasi, sebaiknya dilakukan pada 72 jam setelah trauma. Untuk usaha mengembalikan struktur kerangka wajah bagian dan estetika, fiksasi menggunakan mini-plate lebih menguntungkan. Untuk menghindari defisit jaringan lunak, seluruh wajah direduksi pada saat yang sama,

\section{Daftar Pustaka}

1. Boffano P, Kommers SC, Karagozoglu KH, Forouzanfar T. Aetiology of maxillofacial fractures: a review of published studies during the last 30 years. Br J Oral Maxillofac Surg. 2014;52:901-6.

2. VandeGriend ZP, Hashemi A, Shkoukani M. Changing trends in adult facial trauma epidemiology. J Craniofac Surg. 2015;26:108-12.

3. Uday J. Maureen M. Management of the Traumatized Airway. Anesthesiology 2016; 124:199-206.

4. Czerwinski M, Parker WL, Correa JA, Williams
HB. Effect of treatment delay on mandibular fracture infection rate. Plast Reconstr Surg. 2008; 122:881-5.

5. Ellis E. Condylar process fractures of the mandible. Facial Plast Surg. 2000;16:193-205.

6. Hermund NU, Hillerup S, Kodof T, Schwartz $\mathrm{O}$, Andreasen JO. Effect of early or delayed treatment upon healing of mandibular fractures: a systematic literature review. Dent Traumatol. 2008;24:22-6.

7. Curtis W, Horswell BB. Panfacial fractures: an approach to management. Oral Maxillofac Surg Clin North Am 2013;25(4): 649-60

8. Nastri AL, Gurney B. Current concepts in midface fracture management. Curr Opin Otolaryngol Head Neck Surg 2016;24(4): 36875

9. Anne-Frederique Chouinard, Maria J. Troulis, Edward T. Lahey. The Acute Management of Facial Fractures. Curr Trauma Rep. 2016;2:55-6.

10. Yang R, Zhang C, Liu Y, Li Z, Li Z. Why should we start from mandibular fractures in the treatment of panfacial fractures? J Oral Maxillofac Surg 2012;70:1386-92. 